Borneo Journal of Science \& Technology, Volume (2), Issue (2), Pages: 34-38

DOI: http://doi.org/10.3570/bjost.2020.2.2-06

e-ISSN: 2672-7439

(C) 2018, UCTS Publisher.

Submitted: $05^{\text {th }}$ April 2020

Accepted: $01^{\text {st }}$ June 2020

Published: $31^{\text {th }}$ July 2020

\title{
Estimation of Gross Primary Productivity (GPP) using Moderate Resolution Imaging Spectroradiometer (MODIS)
}

\author{
${ }^{1 *}$ Noor Jemali, ${ }^{1}$ Norliyanatahsya Alias, ${ }^{1}$ Shaparas Daliman, ${ }^{1}$ Aisya Syazana Adeli \\ and ${ }^{1,2}$ Nur Kyairatul Syafinie Abdul Majid \\ ${ }^{1}$ Faculty of Earth Science, Universiti Malaysia Kelantan (UMK), Jeli, 17600, Malaysia \\ ${ }^{2}$ Institute of Tropical Forestry and Forest Product (INTROP), Universiti Putra Malaysia (UPM), \\ 43400, Malaysia
}

\begin{abstract}
This study investigates the performances of satellite imagery data from Moderate Resolution Imaging Spectroradiometer (MODIS) in estimating gross primary production (GPP) in Kelantan. The quantitative estimation of GPP is calculated through a light use efficiency model (LUE) and enhanced vegetation index (EVI) as a proxy of greenness to address spatial and temporal variation in terrestrial photosynthetic activities. GPP is the amount of carbon captured by plants and it is an important biophysical parameter in the spatio-temporal dynamics of carbon dioxide. Estimation of GPP is important for natural resource and land management, regional carbon cycle analysis, ecosystem status assessment, and environmental change monitoring. The MODIS data products of MOD15 FPAR and MOD17A2H were acquired and analyzed. The GPP value was calculated from MODIS data and the product are classified into a different range of categories in the image classifications process. The estimation of GPP in Kelantan was up to $646 \mathrm{gC} / \mathrm{m}^{2} / \mathrm{month}$. The highest value of GPP $\left(646 \mathrm{gC} / \mathrm{m}^{2} / \mathrm{month}\right)$ was found in Chiku, Gua Musang district. The main vegetation detected in this area were oil palm and the surrounding areas covered with intact forests. Meanwhile, the lowest GPP ( 0 to $100 \mathrm{gC} / \mathrm{m}^{2} / \mathrm{month}$ ) was estimated in Kota Bharu, Tumpat and Bachok districts where least vegetation with numbers of land developments was found in these areas. MODIS can be used to estimate GPP with efficient time, cost and energy and this preliminary study will be helpful for the development of future GPP estimation models. However, further study needed to enhance the accuracy of estimation of GPP, especially in different land-use type in Kelantan.
\end{abstract}

Keywords: Gross Primary Production, MODIS, Enhanced Vegetation Index, Remote Sensing.

\section{INTRODUCTION}

Satellite images with vegetation indices data offer a convenient tool in estimating primary production of a large-scale area [1]. The estimation of gross primary production (GPP) is an imperative parameter for carbon cycle study and it is basically calculated based on the overall rate of carbon fixation through the photosynthesis process. The study of GPP provides important information about the environment. Hence, it also acts as a critical component of the global carbon cycle measurements.

The usage of a Moderate Resolution Imaging Radiometer (MODIS), is one of geospatial technique that can aid to estimate GPP on a large scale. MODIS is a multipurpose satellite instrument that observes physical variables of the land, ocean, and atmosphere with wide spectral range and spatial resolution [2]. MODIS sensor installed on the Terra and Aqua Satellites has been used widely to study the global carbon cycle associated with terrestrial ecosystems. Estimation of GPP is important for natural resource and land management, regional carbon cycle analysis, ecosystem status assessment, and environmental change monitoring. The quantification of GPP would assist in computing total carbon in a large area with efficient time, energy and workforce.

In Malaysia, our tropical forest area covers about 5.7 million ha [3], and this area is important in the control of regional and global climate [4]. However, there is still a lack of studies in estimating primary production for the tropical region [5]. Therefore, the goals of the present study were to evaluate the performance of existing MODIS products in estimating the gross primary productivity in Kelantan.

Corresponding Author: Noor Jemali, Universiti Malaysia Kelantan (UMK), E-mail: janatunnaim@umk.edu.my 


\section{MATERIALS AND METHODS}

\section{Study area}

The selected study sites located in Kelantan, which lies in the north-east of Peninsular Malaysia with geographical position between $4.6123^{\circ} \mathrm{N}, 101.9081^{\circ} \mathrm{E}$ to $6.1991^{\circ} \mathrm{N}, 102.1694^{\circ} \mathrm{E}$. The capital city of Kelantan is Kota Bharu. Kelantan has a total area of about 15,000 $\mathrm{km}^{2}$ (4.4 per cent of the total area of Malaysia) with various land cover and land use types (Figure 1). Eighty-five percent of the state covered by forest [3]. The forests include Permanent Reserved Forest, Inland Forest, Mangrove, Peat Swamp Forests, Hill Dipterocarp Forest and Lowland Dipterocarp Forests [6]. Administratively, Kelantan is divided into ten districts named Tumpat, Kota Bharu, Pasir Mas, Pasir Puteh, Bachok, Tanah Merah, Jeli, Machang, Kuala Krai, and Gua Musang [7].

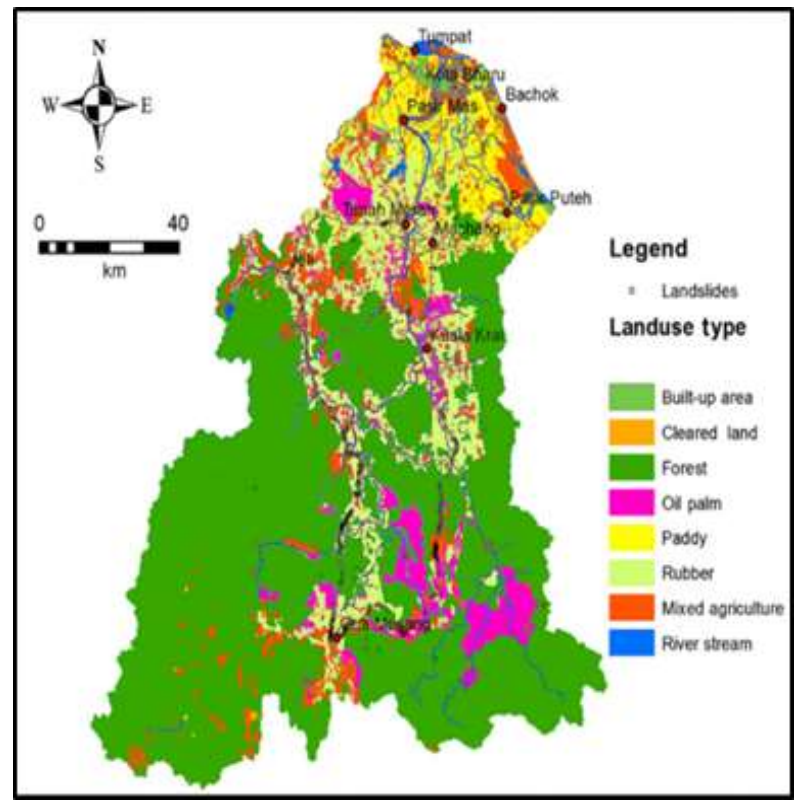

Figure 1: Land cover and land use type of study area

\section{Image data}

Secondary data from remote sensing satellite images named Moderate Resolution Imaging Radiometer (MODIS) was utilized in this study. The MODIS product of MOD15 FPAR (Figure 2) and MOD17A2H (Figure 3) dated in June 2019 were used in this study. The data was downloaded from the United States Geological Survey (USGS) website. The resolution of these MODIS data is $1 \times 1 \mathrm{~km}$. Each MODIS data acquired was in 36 spectral bands ranging from $450 \mathrm{~nm}$ to $2100 \mathrm{~nm}$. From the 36 spectral bands, seven bands were designed for the study of vegetation and land surface: blue (459-479 $\mathrm{nm})$ - band 3, green (545-565 $\mathrm{nm})$ - band 4, red (620-670 nm) - band 1, near-infrared NIR (841-875 nm, 1230-1250 nm) - band 2 and 5, and short wave infrared SWIR (1628-1652 nm, 2105-2155 $\mathrm{nm})$ - band 6 and 7. The data were analyzed using ENVI and ArcMap version 10.3 software for classification and area calculation.

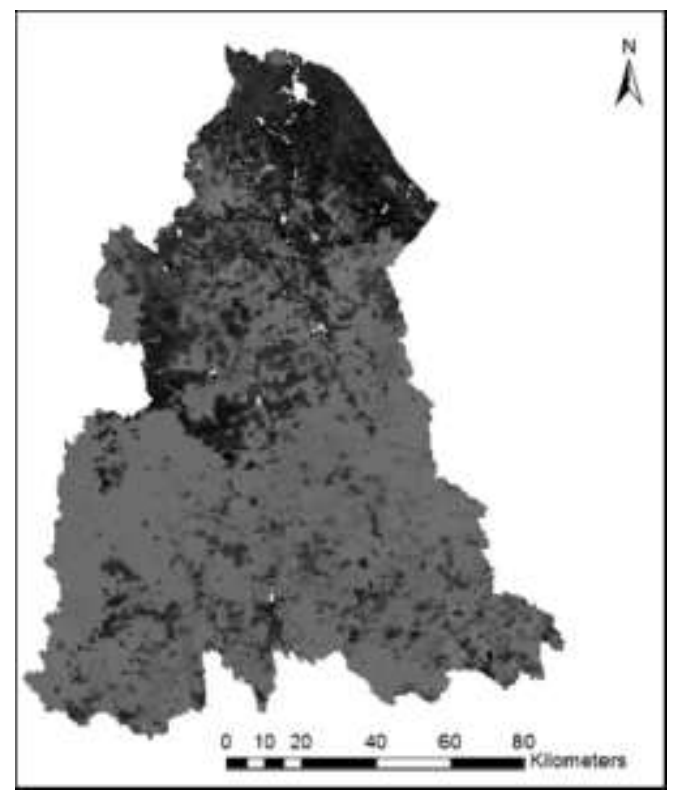

Figure 2: MODIS product of MOD15 FPAR

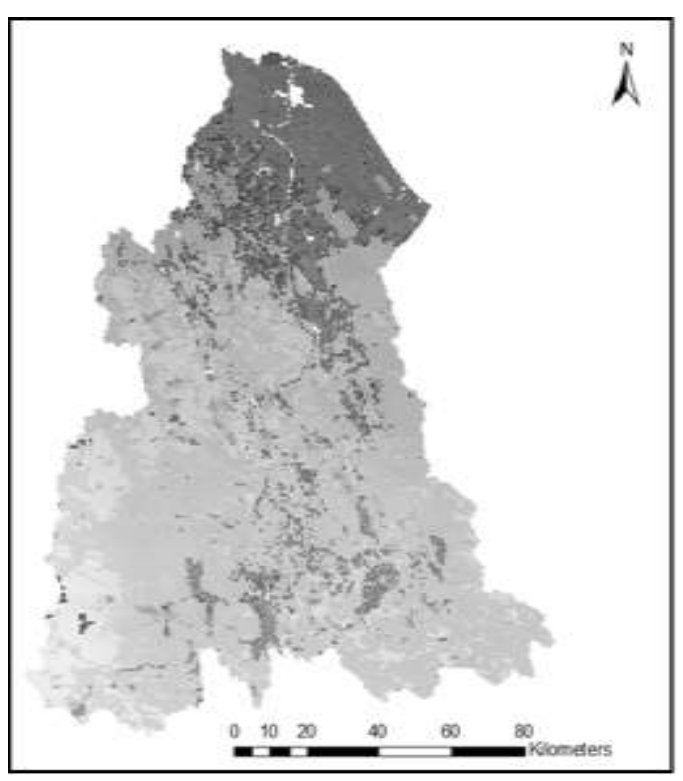

Figure 3: MODIS product of MOD17A2H 


\section{Image analysis}

The MODIS data was run for a pre-processing stage. At this level, unwanted noise and geometric errors were reduced in order to obtain the desired image before image analysis will be carried out. The preprocessing step will enhance image data quality by reducing or eliminating numerous radiometric and geometric errors due to internal and external conditions [8]. In this study, pre-processing of images include image enhancement, pixel brightness transformation, projection of data by geometric transformation process and image clipping process were carried out for both MOD15 and MOD17 images. ENVI software version 5.1 was utilized in this process.

Next step is to overlay the pre-processed images of MOD15 and MOD17. Based on the overlaid images, the GPP value was calculated. The calculation of GPP is using the standard method developed by [9].

$$
\mathrm{GPP}=\varepsilon_{\max } \times 0.45 \times \mathrm{SW} \text { rad } \times \text { fAPAR } \times f(\text { VPD }) \times f\left(\mathrm{~T}_{\min }\right)
$$

Where,

$\varepsilon_{\text {max }}$ - maximal LUE,

$S W_{\text {rad }}$ - short-wave solar radiation

f PAR - $45 \%$ is assumed

$\mathrm{f}(\mathrm{VPD})$ and $f\left(T_{\min }\right)$ - reduction scalars for water stress and low temperature.

The $\varepsilon_{\max }$ is obtained from lookup tables based on vegetation type. $f\left(T_{\min }\right), \mathrm{f}(\mathrm{VPD})$, and $S W_{\text {rad }}$ were obtained from large spatial-scale meteorological data sets available from the NASA Data Assimilation Office (DAO) repository (http://gmao.gsfc.nasa.gov/).

After the calculation of GPP in each pixel, image classification was carried out using maximum likelihood algorithm in a supervised classification method. The process of image classification includes transforming multi-band raster imagery into a singleband raster with a variety of categorical classes related to different land cover types. Seven classes of GPP values were set up in this study. These processes were completed using ArcMap version 10.3 software. The classified GPP values were verified using Google Earth images on the same period of MODIS images acquisition date to access the accuracy of GPP value calculated in this study.

\section{RESULTS AND DISCUSSION}

Image classification result showed in Figure 4 explained the distribution of GPP in Kelantan. The estimation of GPP in Kelantan based on this study were ranged from 0 to $646 \mathrm{gC} / \mathrm{m}^{2} / \mathrm{month}$. In average, GPP in Kelantan was at $428.63 \mathrm{gC} / \mathrm{m}^{2} /$ month with a standard deviation of $143.20 \mathrm{gC} / \mathrm{m}^{2} / \mathrm{month}$. From the minimum and maximum range of GPP values, seven classes of GPP value ranges were setup in this study. Table 1 shows the range value of GPP with percentage and the total area covered in hectares.

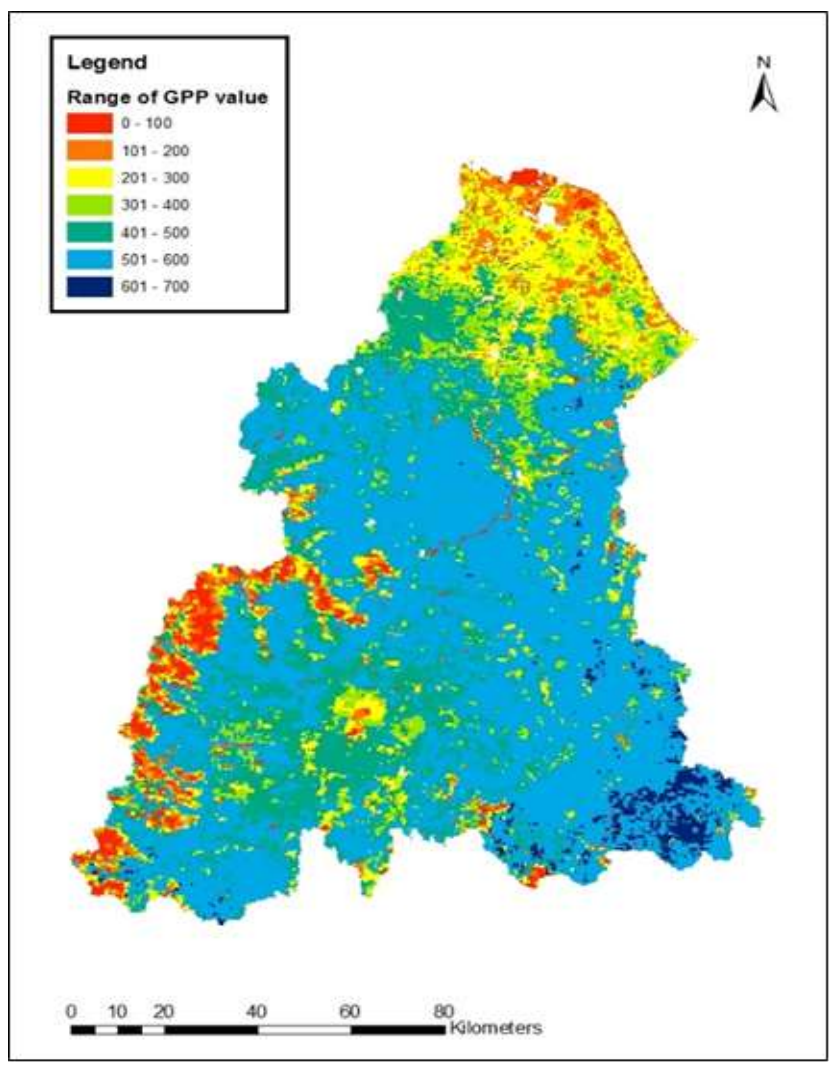

Figure 4: Distribution of GPP in Kelantan

From the result, 52.2 per cent of the Kelantan area consists of GPP value between 501 to $600 \mathrm{gC} / \mathrm{m}^{2} /$ month. These areas were mostly found in part of Gua Musang, Kuala Krai, Jeli, Tanah Merah and also Machang districts. There is a huge area of the forest reserve is located in this area which could sequester the huge amount of carbon due to a large number of tree stands [10]. The highest estimated GPP was clearly observed in Chiku, Gua Musang district. The GPP value was a range at 601 to 700 covering $2.2 \%$ from the total area of Kelantan. The GPP values for land use types related to greenspaces of the area, therefore this result was further checked with Google earth on the same period of MODIS data acquisition. The main vegetation identified in the area is oil palm and the area is also surrounded by intact forests.

The lowest GPP value that ranges between 0-100 $\mathrm{gC} / \mathrm{m}^{2} /$ month was further investigated by its location and current land use. The area of Kota Bharu, Tumpat and 
Bachok were recorded at low GPP among other districts.

Small GPP value of these areas was due to low vegetation detection and quite a high rate of development is happening in this area. A lower value of GPP can be explained due to differences in biomass that may be imposed by two factors. Firstly, biomass was influenced by vegetation density. Low biomass carbon storage was detected due to less number of emergent trees compared to the presence of shrubs [10]. Secondly, the small value in biomass may also be influenced by both biogenic and anthropogenic disturbances. Anthropogenic activities such as urban expansion, land development, deforestation, forest clearing, clearcutting had lower the number of biomass or total carbon [11] which had cause lower estimation of GPP value.

Table 1: GPP value and distribution of area

\begin{tabular}{ccc}
\hline GPP value & Area (ha) & Percentage (\%) \\
\hline $0-100$ & 47351.4 & 3.2 \\
$101-200$ & 76354.2 & 5.2 \\
$201-300$ & 146297.9 & 9.9 \\
$301-400$ & 112270.8 & 7.6 \\
$401-500$ & 293155.8 & 19.8 \\
$501-600$ & 772550.2 & 52.2 \\
$601-700$ & 32321.0 & 2.2 \\
\hline
\end{tabular}

The previous study by [10] found that the total biomass and carbon stock of standing trees in Bukit Bakar Forest Reserve, Gunung Basor and Gunung Stong Tengah recorded a high accumulation or carbon stock in Kelantan. It is also estimated that the lower altitude produces the highest value of biomass. This study supports the finding of the previous researches. However, the results obtained in this study only touched the prevailing areas of Kelantan. More work is required to understand the spatial and temporal variations in productivity parameters of the estimation of GPP in especially in different land use and vegetation type in the tropical region.

\section{CONCLUSION}

A recent study indicates that the estimation of GPP in Kelantan was ranged from 0 to $646 \mathrm{gC} / \mathrm{m}^{2} /$ month. The highest value of GPP $\left(646 \mathrm{gC} / \mathrm{m}^{2} / \mathrm{month}\right)$ was found at Chiku, Gua Musang district while the lowest value of GPP (0 to $100 \mathrm{gC} / \mathrm{m}^{2} /$ month) was found at Kota Bharu, Tumpat and Bachok districts. MODIS data can be used to estimate GPP value with efficient time, cost and energy. This evaluation of satellite-driven carbon productivity is important for quantifying the role of vegetation in the global or regional carbon cycle. It is also essential in assessing the quality of the forest and contribute information to the management of the forest. Further studies related to the uses the MODIS data in different tropical types of vegetation need to be undertaken in the future to enhance the accuracy of estimation. This results will also be helpful for the development of future GPP estimation models.

\section{ACKNOWLEDGMENT}

This study is financially supported in part by Universiti Malaysia Kelantan (UMK) and the Fundamental Research Grant Scheme (FRGS) (R/FRGS/A08.00/01237A/001/2017/ 000441).

\section{REFERENCES}

[1] Wu, C., Niu, Z., and Gao, S. 2010. Gross Primary Production Estimation from MODIS Data with Vegetation Index and Photosynthetically Active Radiation In Maize. Journal of Geophysical Research. 115(D12127). doi:10.1029/2009JD0 13023.

[2] Justice, C.O., Vermote, E., Townshend, J.R.G., Defries, R., Roy, D.P., Hall, D.K., Salomonson V.V., Privette J.L., Riggs G., Strahler, A., Lucht, W., Myneni, R.B., Knyazikhin, Y., Running, S.W., Nemani, R.R., Wan, Z.A., Huete, R., van Leeuwen, W., Wolfe, R.E., Giglio, L., Muller, J., Lewis, P., and Barnsley, M.J.1998. The moderate resolution imaging spectroradiometer (MODIS): land remote sensing for global change research. IEEE Transactions on Geoscience and Remote Sensing. 36 (1998), 1228-1249.

[3] Forestry Department of Peninsular Malaysia (FDPM). Forestry Statistic Peninsular Malaysia, 2017, https://www.forestry.gov.my/my/pusatsumber/2016-06-07-03-12-29.

[4] Jabatan Perhutanan Negeri Kelantan (JPNK). 2018. http://jpnk.kelantan.gov.my/index.php?

option=com_content $\&$ view $=$ article $\&$ id $=46 \& I t e m i d=$ 385\&lang=en

[5] Deborah A. Clark, Sandra Brown, David W. Kicklighter, Jeffrey Q. Chambers, John R. Thomlinson, Jian $\mathrm{Ni}$ and Elisabeth A. Holland. 2001. Net Primary Production in Tropical Forests: An Evaluation and Synthesis of Existing Field Data. Ecological Applications.11 (2). 371-384.

[6] Omar, H., Misman, M. and Kassim, A. 2017. Synergetic of PALSAR-2 and Sentinel 1A SAR polarimetry for retrieving aboveground biomass in dipterocarp forest of Malaysia. Applied Sciences, 7(675):1-20.

[7] Navarro, M.N.V., Jourdan, C., Sileye, T., Braconnier, S., Mialet-serra, I., Saint-andre L., Dauzat, J., Nouvellon, Y., Epron, D., Bonnefond, 
J.M., Berbigier, P., Rouziere, A., Bouillet, J.P., and Roupsard, O.2008. Fruit development, not GPP, drives seasonal variation in NPP in a tropical palm plantation. Tree Physiology. 28(1).1661-1674.

[8] Pour A. B., and Hashim M. 2017. Application of Landsat-8 and ALOS-2 data for structural and landslide hazard mapping in Kelantan, Malaysia. Natural Hazards and Earth System Sciences 17(7). 1285.

[9] Running S.W., Nemani R.R., Heinsch F. A., Zhao M., Reeves M., and Hashimoto H. 2004. A continuous satellite-derived measure of .global terrestrial primary production. Bioscience 54(6). 547-560.
[10] Norashikin F., Kamarul H., Aisyah N., Ibrahim B. and Yew S.K. 2017. Biomass and carbon stock estimation along different altitudinal gradients in the tropical forest of Gunung Basor, Kelantan, Malaysia. Malayan Nature Journal. 69.57-62.

[11] Kathirithamby-Wells J.2006. Nature and nation: forests and development in Peninsular Malaysia. NIAS Press, 2006. 